\section{Bile duct ligature in young rats: A revisited animal model for biliary atresia}

\author{
Matías Garrido, ${ }^{1,2}$ Camila Escobar, ${ }^{1}$ \\ Constanza Zamora, ${ }^{1}$ Carolina Rejas, ${ }^{1}$ \\ Juan Varas, ${ }^{1}$ Mario Párraga, ${ }^{1}$ \\ Sebastián San Martín, ${ }^{1}$ \\ Sandra Montedonico ${ }^{1,2}$ \\ ${ }^{1}$ Centro de Investigaciones Biomédicas, \\ Universidad de Valparaíso \\ ${ }^{2}$ Servicio de Cirugía Pediátrica, Hospital \\ Carlos Van Buren, Valparaíso, Chile
}

\section{Abstract}

Biliary atresia leads to cirrhosis in the vast majority of patients and constitutes the first cause of paediatric liver transplantation. Animal models allow us to understand the molecular basis and natural history of diseases. The aim of this study is to describe a surgically created animal model of biliary atresia with emphasis in long-term liver function. Forty-two 3-week-old SpragueDawley rats were randomly divided into two groups: bile duct ligature (BDL) and control. The animals were sacrificed on the $2^{\text {nd }}, 4^{\text {th }}$, and $6^{\text {th }}$ postoperative weeks. Blood samples were collected for liver function analysis. The spleen to body weight ratio was determined. Histopathological examination of liver tissue was performed by hematoxylin-eosin and Sirius red staining. Collagen quantification was determined by using colorimetric digital image analysis and was expressed as a percentage of total liver tissue area. Quantitative real-time polymerase chain reaction was performed to analyse gene expression levels of transforming growth factor- $\beta 1(T g f b 1)$ and apeline $(A p l n)$ genes. Statistical analysis was performed where $\mathrm{P}<0.05$ was considered significant. Animals from BDL group developed increasing cholestasis with clinical and laboratory features. Splenomegaly was detected at $4^{\text {th }}$ and $6^{\text {th }}$ week $(\mathrm{P}<0.05)$. Histological evaluation of the liver showed ductular reaction, portal fibrosis and bile plugs. Collagen area to total liver tissue area had a median of $2.5 \%$ in the control group and $6.5 \%, 14.3 \%$ and $37.7 \%$ in BDL rats at $2^{\text {nd }}, 4^{\text {th }}$ and $6^{\text {th }}$ weeks, respectively $(\mathrm{P}<0.001)$. Tgfbl mRNA expression level was significantly higher at $6^{\text {th }}$ week $(\mathrm{P}<0.001)$ in $\mathrm{BDL}$ group when compared to control. Apln mRNA expression level was significantly higher at $4^{\text {th }}$ and $6^{\text {th }}$ week $(\mathrm{P}<0.001)$ and showed a positive linear cor- relation $(\mathrm{r}=0.975, \mathrm{P}<0.05)$ in $\mathrm{BDL}$ group when compared to control. Bile duct ligature in young rats is an animal model that recreates clinical, laboratory, histological and molecular findings of biliary atresia. Bile duct ligature constitutes a good animal model to investigate therapeutic approaches for modifying the progression of liver fibrosis in biliary atresia.

\section{Introduction}

Biliary atresia (BA) is a cholestastic neonatal disease of unknown etiology characterized by progressive, inflammatory, and fibrosclerosing cholangiopathy resulting in obstruction of both extrahepatic and intrahepatic bile ducts. ${ }^{1}$ Clinically, biliary atresia is classified into three groups: cystic biliary atresia, biliary atresia with other congenital malformations, and isolated biliary atresia. ${ }^{2}$ The incidence of isolated biliary atresia is higher in Asian countries and French Polynesia (1:2700-3500) compared to Europe and North America (1:500018,000). ${ }^{3}$ Kasai et al. described the classical portoenterostomy in 1957 and this has been the surgical treatment since then. ${ }^{4}$ However, despite surgery $68-80 \%$ of patients affected by biliary atresia develop progressive fibrosis leading to biliary cirrhosis and portal hypertension. Biliary atresia constitutes the most common diagnosis leading to pediatric liver transplantation, accounting for half of cases. $^{5}$

Animal models play a key role in our understanding of the molecular basis and natural history of diseases. Three types of animal models have been reported in biliary atresia: spontaneous, secondary to viral infection and surgically created. ${ }^{6}$ The sea lamprey (Petromyzon marinus) is a spontaneous animal model of biliary atresia. The sea lamprey is a jawless vertebrate that during metamorphosis from larvae to parasitic juveniles progressively loses the biliary system until complete biliary degeneration. However, sea lamprey does not develop cirrhosis during developmental biliary atresia.?

Intraperitoneal inoculation of mice with rhesus rotavirus within the first $48 \mathrm{~h}$ of postnatal life leads to injury of the biliary epithelium and subsequent transient extrahepatic biliary obstruction and intrahepatic bile duct proliferation during the neonatal period. These features validate the use of the viral murine model as a tool to study the pathogenesis of human biliary atresia. However, in contrast to human biliary atresia, rhesus rotavirus animal model develops a much less intensive liver fibrosis and
Correspondence: Dr. Sebastián San Martín, Centro de Investigaciones Biomédicas, Universidad de Valparaíso, Edificio Bruno Günther, Hontaneda 2664, Valparaíso, Chile.

Tel. +56.32 .2507368$

E-mail: sebastian.sanmartin@uv.cl

Key words: Biliary atresia; animal models; bile duct ligature; collagen; $T g f \beta$; Apelin.

Acknowledgments: the authors thanks to Nicolas Cáceres by the arrangement of the instruments for carrying out blood tests to rats, Claudio Córdova for the support with the collagen quantification method, and Christian Papusinzki for the statistical analysis. This project received financial support from Centro de Investigaciones Biomédicas (CI 05/2006), Universidad de Valparaíso, Chile.

Received for publication: 2 May 2017. Accepted for publication: 1 August 2017.

This work is licensed under a Creative Commons Attribution-NonCommercial 4.0 International License (CC BY-NC 4.0).

(C) Copyright M. Garrido et al., 2017

Licensee PAGEPress, Italy

European Journal of Histochemistry 2017; 61:2803 doi:10.4081/ejh.2017.2803

without portal hypertension. ${ }^{6,7}$ Other limitations of this model are: timing and dosing of virus application affect the reproducibility of the model; injection-related injury to abdominal organs is usually fatal; cannibalization of pups impedes the harvest of valuable specimens and sequential investigations cannot be performed in the same animal because pups are extremely unstable and too small for performing repeated biopsies and blood samplings. Moreover, the survival rate of pups in rhesus rotavirus mice is only $10 \%$ at 3 weeks of age. ${ }^{6}$

Bile duct ligature (BDL) is a surgically created animal model developed by Cameron and Oakley in 1932 that consist in ligation or excision of the common bile duct. ${ }^{8}$ BDL has been the most useful experimental model to study cholestatic disease and is an important model to study portal hypertension and hepatopulmonary syndrome due to the possibility of long-term follow up. BDL model has been performed mainly in adult rats..$^{9,10}$ However, it is likely that natural history of cholestatic injury is different in adults compared to young animals. ${ }^{11}$

The aim of this study is to describe a surgically created experimental model of BA in young animals with emphasis in long-term liver function. 


\section{Materials and Methods}

\section{Animals}

Forty-two 3-week-old Sprague-Dawley rats (weighing 40.5-73.2 g, mean 53.2 \pm 7.9 g) were used in the experiments and divided into two groups: experimental group $(n=21)$ and control group $(n=21)$. The puppies were kept with their mothers until surgery at three weeks of age. They had access to drink and food ad libitum, circadian cycle of light-darkness 12:12 h, controlled humidity $(40-70 \%)$ and temperature $\left(21 \pm 2^{\circ} \mathrm{C}\right)$, with ventilation of 10 changes air/h.

The study was approved by the Institutional Bioethics Committee for Animal Research of Universidad de Valparaíso (BEA029-2014). It was carried out according to the International Guiding Principles regarding the use of laboratory animals. $^{12}$

\section{Surgical procedure}

One hour before the operation, acetaminophen $0.1 \mathrm{~mL}(10 \mathrm{~g} / 100 \mathrm{~mL})$ was administered by oral route. The animal was placed in a transparent acrylic box especially designed for anesthesic induction of young rats. The rat was pre-oxygenated with $99.5 \pm 0.5$ pure oxygen at $1 \mathrm{~L} / \mathrm{min}$ by $30 \mathrm{~s}$, and then anesthetized with isoflurane at 3-4\% with an isoflurane funnel-fill vaporizer (Harvard Apparatus, Holliston, MA, USA) until assessed by the absence of voluntary movements, muscle relaxation and loss of response to stimuli reflexes. The abdomen was shaved and cleaned with chlorhexidine gluconate soap 2\%. After that, the rat was attached to a heated small animal operating table (Harvard Apparatus). The anaesthesia was maintained by a facial mask with oxygen and isoflurane $2 \%$. The surgical procedure was performed under clean conditions, using surgical loupes (magnification 2.5x) and microsurgical instruments. A superior midline abdominal incision was performed. The viscera were exposed; the duodenum was exteriorized and the common bile duct was identified and dissected. After that, the common bile duct was ligated in two parts: a distal ligature was placed just before the entrance to the pancreas and a proximal ligature was placed below the hepatic duct junction with nonabsorbable monofilament polypropylene suture 7-0 (Covidien, Dublin, Ireland). After that, the common bile duct was sectioned in the middle, in order to avoid re-canalization. The abdomen was closed in two-layers. In the control group, rats underwent the same anesthesia and abdominal incision and clo- sure, but the common bile ducts were not ligated and sectioned. During anesthetic recovery, the rat was exposed to infrared light to prevent hypothermia for $30 \mathrm{~min}$, and received oxygen until awake. After surgery, the rat was allowed to feed normally.

\section{Euthanasia and collection of samples}

Rats were sacrificed on the $2^{\text {nd }}, 4^{\text {th }}$, and $6^{\text {th }}$ postoperative weeks, under general anesthesia with isoflurane $4 \%$ according to the International Guiding Principles regarding the use of laboratory animals. ${ }^{12}$ Weight gain (grams) was recorded before killing. A laparotomy was performed describing the intra-abdominal anatomy focusing in liver aspect and biliary duct changes.

\section{Biochemical liver function analysis}

Blood samples were collected by puncture with a 21-gauge needle from the infrahepatic inferior cava vein at time of euthanasia. These were centrifuged at 1000 rpm by $3 \mathrm{~min}$ and analyzed by VetTest ${ }^{\circledR}$ Chemistry Analyzer (Idexx Laboratories, Westbrook, ME, USA), according to fabricant instructions, adjusting by species and age of animals. The following liver function tests were studied: albumin, alkaline phosphatase, aspartate transaminase (AST), alanine transaminase (ALT), gamma-glutamyl transpeptidase (GGT) and total bilirubin.

\section{Determination of spleen index}

The spleen was extracted and weighed (grams) in order to obtain an indirect measurement of portal hypertension expressed as "spleen index": spleen weight/body weight x $100 .{ }^{9}$

\section{Histopathological examination}

The left lateral lobe of the liver was subject to histological evaluation. The lobe was divided into two samples: one of them was kept in 4\% buffered paraformaldehyde, embedded in paraffin, sectioned and stained with hematoxylin-eosin following conventional protocols to obtain the final block. The second sample was fixed in methacarn solution (methanol, chloroform, acetic acid; 6:3:1) during $4 \mathrm{~h}$ at $4^{\circ} \mathrm{C}$. After that, samples were dehydrated in $100 \%$ ethanol, cleared in xylol and embedded in paraffin. Five$\mu \mathrm{m}$-thick histological sections were cut and stained in a Sirius-red solution $(0,1 \% \mathrm{v} / \mathrm{v})$ for $1 \mathrm{~h}$. Sirius red is a strongly acidic and elongated dye molecule that reacts with basic groups of collagen molecules. This is a sensitive and specific staining method that has the advantage of permitting easy and precise localization of the tissue components containing oriented collagen molecules, permitting a close morphological observation and allowing quantification methods. ${ }^{13}$ The slides were analyzed in a light microscope (Olympus ${ }^{\circledR}$ CX81, Olympus, Tokyo, Japan) and photographed (DP71 camera, Olympus). Images at 40x, $100 \mathrm{x}$ and $400 \mathrm{x}$ magnification were captured.

\section{Collagen quantification}

Ten non-overlapping photographs from random fields per section were taken from two slides per specimen at 100x magnification. Images were exported in .jpg format with a resolution of $1200 \times 900$ pixels in RGB color palette. Images were processed in an automated image analyzer (ImageJ version 1.48, U.S. National Institutes of Health, Bethesda, MA, USA). Threshold colors were adjusted using the HueSaturation-Brightness (HSB) combination to select all the positive Sirius red marking according to controls. Selected area was measured in square pixels and the staining intensity was measured in an 8-bit gray scale ( 0 to 256$)$. The positive area fraction considering a complete picture of the same resolution was calculated. The process of analysis was automated using macrocode to process 10 images per cycle. Data were expressed as a percentage of total liver tissue area.

\section{Gene expression}

A sample of the left lateral lobe of the liver was frozen in liquid nitrogen and used for gene expression analysis. Total RNA was extracted using TRIzol ${ }^{\circledR}$ RNA isolation reagent (Ambion, Thermo Fisher Scientific, Waltham, MA, USA) according to the manufacturer's recommendations. Template cDNA was obtained by reverse transcription of $2 \mu \mathrm{g}$ of total RNA using MMLV retrotranscriptase (NEB, Ipswich, MA, USA). Reaction mixtures were incubated at $25^{\circ} \mathrm{C}$ for $10 \mathrm{~min}, 42^{\circ} \mathrm{C}$ for $50 \mathrm{~min}$ and $70^{\circ} \mathrm{C}$ for $10 \mathrm{~min}$.

Relative quantification of gene expression levels for transforming growth factor$\beta 1(T g f b 1)$ and apeline $(A p l n)$ genes were carried out by real-time quantitative PCR (qPCR) on EcoPCR real time system (Illumina, San Diego, CA, USA) using cDNA samples obtained as described before. For this purpose, $\mathrm{SYBR}^{\circledR}$ Select Master Mix (Thermo Fisher Scientific) was used according to manufacturer's instructions. Specific primers were designed for amplification of each gene, and their sequences are described below. Comparative cycle threshold $(\mathrm{Ct})$ values were obtained after $\mathrm{qPCR}$ reaction were performed. We used the Ct method to calculate relative mRNA expression. All quantifications were normalized by the correspon- 
ding expression of $\beta 2$ microglobulin $(B 2 \mathrm{~m})$ mRNA that served as a normalizer. In addition, results were corrected with the expression of the same normalized genes in control tissues. Finally, gene expression differences were calculated using data obtained from groups according to the time elapsed after surgery. These differences were shown as "fold change" in the level of expression of both Apln and $T g f b 1$ at 2, 4 and 6 weeks after surgery compared with control group.

The sequences of the primers used in this study were as follows:

- $\quad T g f b 1$ sense primer 5'-AGAGCCCTG-

GATACCAACTA-3' and antisense primer 5'-GACCTTGCTGTACTGTGTGT-3';

- Apln sense primer 5'-TGTCCTCATCCCGTGTGTTC-3' and antisense primer 5'-AAGCACTCACCTCCCTACA-3';

- B2m sense primer: 5'-CAGTTCCACCCACCTCAGAT-3' and antisense primer: 5'-TTTTGGGCTCCTTCAGAGTG-3'.

\section{Statistical analysis}

Data are expressed as median with interquartile range in parenthesis. Nonparametric Mann-Whitney Rank Sum Test was applied to evaluate differences among groups. Correlation coefficient Spearman Rank Order Correlation was also calculated at the assessment of gene expression and postoperative follow-up time. KruskalWallis test was applied to determinate differences among gene expression levels between postoperative weeks for each profibrogenic gene. A $\mathrm{P}$ value $<0.05$ was considered statistically significant. Statistical analysis was performed using STATA software ver. 12.0 (StataCorp LP, College Station, TX, USA).

\section{Results}

Rats in the control group weighed a median of $49.5 \mathrm{~g}$ (48.3-55.6) before surgery, and rats in the BDL group weighed a medi- an of 52.6 $\mathrm{g}$ (46.6-58.1) before surgery $(\mathrm{P}=0.93)$. All the rats in the control group survived the experiments. In BDL group, $19 / 21(90.5 \%)$ rats survived the experiments. In BDL group, cholestasis was clinically evident, characterized by icteric coloration of face muzzle, legs and tail. Additionally, yellowish pigmentation was observed in the gravel of boxes (choluria) and stools were clearly pale (acholia). At laparotomy, bile-stained tissues, ascites, hepatomegaly and cystic dilatation of bile duct stump was observed (Figure 1). All these findings were progressive in time. In addition, poor growth of hair in the surgical wound was observed. Table 1 shows postoperative weight gain, spleen index and collagen quantification. Weight was significantly affected by the BDL procedure during the second and fourth postoperative weeks compared to the control group. By the $6 \mathrm{t}^{\mathrm{h}}$ postoperative week, no weight dif-

ference could be observed. Spleen index was significantly altered in the $4^{\text {th }}$ and $6^{\text {th }}$ postoperative weeks in the experimental group, meaning that a progressive splenomegaly was developed. Collagen quantification as a quantitative method for collagen deposition showed no changes in the control group over the weeks. In the BDL group, a highly significant collagen deposition was seen over the weeks on exponential rise, being highest on the $6^{\text {th }}$ postoperative week.

Table 2 shows biochemical liver function analysis. Bilirubin was the only parameter that showed a significant change over the weeks in the experimental group when compare to the control animals. In BDL group, histological analysis of liver showed ductular reaction, portal fibrosis with collagen deposition and bile plugs. These findings were progressive in time after surgery (Figure 2). Tgfbl mRNA expression level

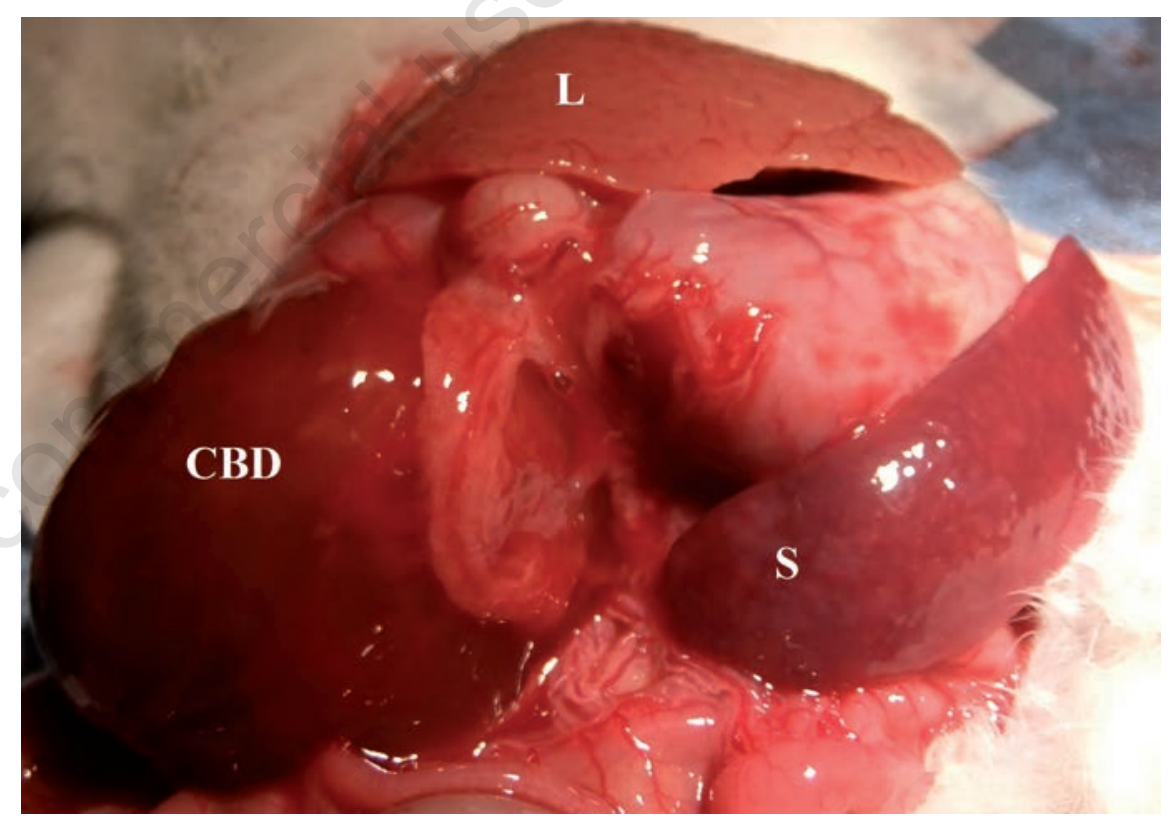

Figure 1. Intraoperative findings at 6 weeks after BDL procedure. Note fibrotic aspect of liver (L), enlarged spleen (S) and cystic dilation of common bile duct (CBD).

Table 1. Comparison between controls and bile duct ligature groups.

\begin{tabular}{llccc} 
& & $2^{\text {nd }}$ P0 week median (IOR) & $4^{\text {th }}$ PO week median (IQR) & $6^{\text {th }}$ PO week median (IQR) \\
Weight at sacrifice (g) & Control & $133(122-136)$ & $222(180-251)$ & $218(213-252)$ \\
& BDL & $84(68-109)^{*}$ & $162(120-179)^{* *}$ & $230(208-257)$ \\
Spleen index & Control & $0.41(0.40-0.43)$ & $0.29(0.28-0.35)$ & $0.24(0.22-0.30)$ \\
(SW/BW x 100) & BDL & $0.44(0.35-0.51)$ & $0.47(0.43-0.68)^{* *}$ & $0.53(0.26-0.74)^{*}$ \\
\hline Collagen quantification (\%) & Control & $2.8(1.3-5.0)$ & $1.7(1.3-2.4)$ & $2.5(1.4-3.7)$ \\
& BDL & $6.5(3.5-15.5)^{* *}$ & $14.3(6.9-33.6)^{* *}$ & $37.7(24.1-48.1)^{*}$ \\
\hline
\end{tabular}

PO, postoperative; IQR, interquartile range; BDL, bile duct ligature; SW, spleen weight. BW, body weight; ${ }^{*} \mathrm{P}<0.05$ versus control group; ${ }^{* *} \mathrm{P}<0.01$ versus control group. 
was significantly higher at $6^{\text {th }}$ postoperative week in BDL compared to control group $(\mathrm{P}<0.001)$, and showed a positive exponential correlation (Figure 3A). Apln mRNA expression level was significantly higher at $4^{\text {th }}$ and $6^{\text {th }}$ postoperative week in BDL compared to control group $(\mathrm{P}<0.001)$, and showed a positive linear correlation $(r=$ 0.975; $\mathrm{P}<0.05$ ) (Figure 3B).

\section{Discussion}

In the past years, a number of authors have stressed the differences in the cholestatic response between adults and young animals after bile duct ligation. Gibelli et al. studied a neonatal BDL model and demonstrated through semiquantitative and quantitative histological analyses a less intense ductal proliferation and inflammatory infiltrate when compared to the adult model. On the other hand, portal and periportal fibrosis were higher when compared to adult animals. ${ }^{11}$ Medeiros et al. showed a slower initial inflammatory response in young animals, but at the end of the study period there was a faster progression to regeneration nodule formation and cirrhosis in young animals. ${ }^{14}$ Omori et al. demonstrated that ductal proliferation and fibrogenesis were more intense in young rats compared to adult animals. ${ }^{15}$ These authors have demonstrated that histological and molecular findings in livers of young rats submitted to BDL were more similar to biliary atresia-related fibrosis. Therefore, it is advisable the use of neonatal or young animals as a surgical animal model to study cholestatic diseases of childhood. However, operating on rat pups is technically difficult because of the small size of biliary structures. Moreover, rat pups are more prone to die during anaesthetic procedures or after surgery. Previous reports have shown a
$66.6 \%$ survival of newborn rats submitted to BDL. ${ }^{11}$ Even in adult rats, BDL has a high mortality (18.1-77.5\%) attributed to sepsis and multiple abscesses. ${ }^{9,10}$ In our study, the survival rate of young rats was superior to previous reports. With appropriate anesthetic agent choice and hypothermia prevention, the animals are able to achieve elevated survival rates. We chose isoflurane as the anesthetic agent, because induction and recovery are more rapid compared to other volatile agents, like halothane, and because it induces less myocardial depression. Moreover, only a small percentage of isoflurane is metabolized in the liver. It is easy to adjust isoflurane depth during maintenance of anesthesia. ${ }^{16}$ In three-week-old rats, ligature of the common bile duct is technically easy to perform and rats can be kept without their mothers during the postoperative period avoiding cannibalism. Moreover, BDL in 3-week-old rats, recreates the histological and molecular features
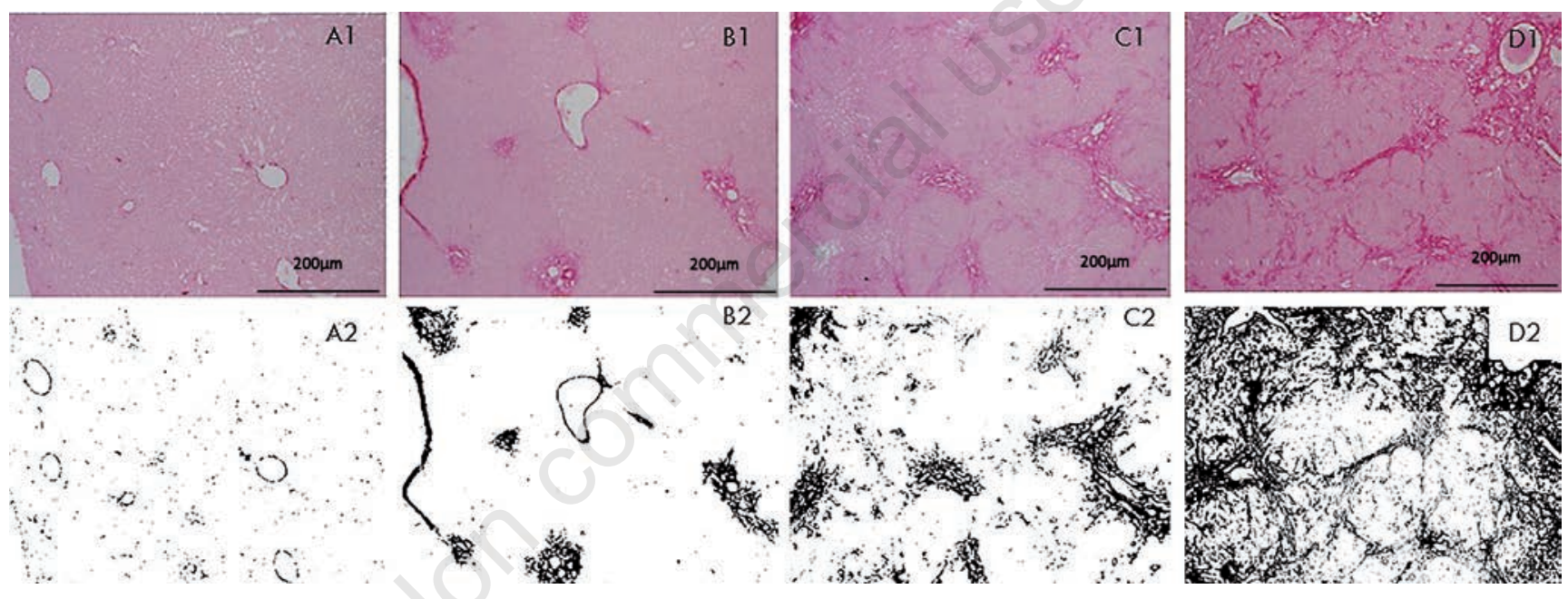

Figure 2. Collagen quantification method by digital image analysis. Liver from control (A1) and bile duct ligature groups on the $2^{\text {nd }}$ $(B 1), 4^{\text {th }}(\mathrm{C} 1)$ and $6^{\text {th }}(\mathrm{D} 1)$ postoperative week, Picrosirius red stain at 100x magnification were taken. Images from control (A2) and bile duct ligature on the $2^{\text {nd }}(\mathrm{B} 2), 4^{\text {th }}(\mathrm{C} 2)$ and $6^{\text {th }}(\mathrm{D} 2)$ postoperative week were created by automated tissue image analysis. Progressive portal fibrosis leading to a massive liver fibrosis on the $6^{\text {th }}$ postoperative week. Scale bars: $200 \mu \mathrm{m}$.

Table 2. Results of biochemical liver function analysis.

\begin{tabular}{|c|c|c|c|c|}
\hline & $\begin{array}{l}\text { Control median (IQR) } \\
\qquad(\mathrm{n}=6)\end{array}$ & $\begin{array}{l}\text { Bile duct ligature } \\
2^{\text {nd }} \text { PO week } \\
\text { median (IQR) } \\
(\mathrm{n}=5)\end{array}$ & $\begin{array}{l}\text { Bile duct ligature } \\
4^{\text {th }} \text { PO week } \\
\text { median (IQR) } \\
(\mathrm{n}=5)\end{array}$ & $\begin{array}{c}\text { Bile duct ligature } \\
6^{\text {th }} \text { PO week } \\
\text { median (IQR) } \\
(\mathrm{n}=5)\end{array}$ \\
\hline Albumin (g/dL) & $2.5(2.5-2.5)$ & $2.4(2.15-2.65)$ & $2.1(2-2.1)$ & $2.1(1.95-2.1)$ \\
\hline $\operatorname{ALT}(\mathrm{U} / \mathrm{L})$ & $70(67.5-72.5)$ & $87(78.5-88.25)$ & $130(74-134)$ & $70(54-99.5)$ \\
\hline AST(U/L) & $61(43.5-78.5)$ & $260(155-353.5)$ & $184(160-201)$ & $247(169-276.5)$ \\
\hline Alkaline Phosphatase (U/L) & $574(538.5-609)$ & $415(390-445.75)$ & $705(542-724)$ & $418(334-506.5)$ \\
\hline GGT (U/L) & $0(0-0)$ & $22(0-46.75)$ & $31(31-45)$ & $23(17.5-43.5)$ \\
\hline Bilirubin (mg/dL) & $0.1(0.1-0.1)$ & $2.75(0.275-5.2)^{*}$ & $3(1.9-4.4)^{*}$ & $3.8(3.6-4.65)^{*}$ \\
\hline
\end{tabular}

PO, postoperative; IQR, interquartile range; ${ }^{*} \mathrm{P}<0.05$ versus control group. 
of biliary atresia. Therefore, 3 weeks old rats have the advantages of both neonatal and adult rat models of bile duct ligature. ${ }^{17}$

At diagnosis, biliary atresia typically presents with conjugated jaundice, pale stools, and dark urine. Failure to thrive is another clinical finding in biliary atresia that results from poor absorption of longchain fats and the catabolic state. ${ }^{1}$ The rats in our study developed jaundice, choluria and acholia following surgical procedure. The catabolic state was inferred from poor growth hair in the abdominal surgical wound. Failure to thrive is noted early in the $2^{\text {nd }}$ postoperative week and maintained up to the $4^{\text {th }}$ postoperative week. Rat weight was similar in control and BDL rats on the $6^{\text {th }}$ postoperative week. We believe that this is due to the development of ascites, hepatomegaly and splenomegaly that can increase body weight as observed in BDL group.

Splenomegaly is not usually found in biliary atresia unless diagnosis is made late. Splenomegaly is a sign of portal hypertension. ${ }^{1}$ In our study, the spleen index was progressively higher as the postoperative weeks passed and as the cirrhosis and portal hypertension developed. Ascites is another feature of portal hypertension also present in this model. Therefore, BDL model in young rats recreate the complications associated to the progression of biliary atresia.

Biochemical variables in biliary atresia typically identify cholestasic liver function test, with increased bilirubin, alkaline phosphatase, gamma-glutamyl transferase, aspartate aminotransferase and alanine aminotransferase. At presentation, albumin value is typically normal. ${ }^{1}$ Our results show a similar pattern in BDL group compared to human biliary atresia. However, only bilirubin was significantly higher with near 40fold elevation compared to control group. We believe that the other liver function tests were not significantly altered due to the limited number of samples studied.

Histopathological liver changes in biliary atresia include ductular reaction, portal fibrosis and bile plugs. Ductular reaction consists in proliferation of small interanastomosing ductules located at the periphery of portal tracts, and represents the most consistent indicator of the presence of biliary obstruction. ${ }^{18}$ Ductular reaction is typically accompanied by portal fibrosis and portal and periductal edema. Mild lymphocytic inflammation is usually present within portal tracts in biliary atresia. Other inflammatory cells include eosinophils, plasma cells, and macrophages. Bile plugs are frequently seen within dilated lumens of ducts and represent another useful diagnostic feature. ${ }^{19}$
Liver fibrogenesis is a dynamic wound healing-like process that leads to progressive accumulation of extracellular matrix components in an attempt to limit hepatic damage. Biliary atresia-related fibrosis is more rapid and aggressive than any other adult liver disease. Biliary fibrosis pattern is characterized by formation of portal - portal fibrotic septa surrounding liver nodules. This pattern develops by preserving connection between central vein and portal tract and is typically associated to intense proliferation of reactive bile ductules and periductular myofibroblasts. ${ }^{20}$

In the present study, we found a progressive liver fibrosis over the weeks, with a massive fibrosis on the $6^{\text {th }}$ postoperative week. These findings demonstrate that BDL model in young rats clearly reproduces hepatic histological features of biliary atresia and specifically recreates progressive collagen deposition as observed in the human pathological condition.

TGF- $\beta$ is a central regulator in chronic liver diseases that contributes to all stages of disease progression from initial liver injury through inflammation and fibrosis to cirrhosis and hepatocellular carcinoma. Three isoforms of TGF- $\beta$ have been identified $(\beta 1, \beta 2$, and $\beta 3)$, but only TGF- $\beta 1$ is linked to liver fibrogenesis. ${ }^{21}$ TGF- $\beta 1$ is considered as a major profibrogenic cytokine. $.^{22} \mathrm{TGF}-\beta 1$ regulates a wide variety of cellular processes in liver fibrogenesis,

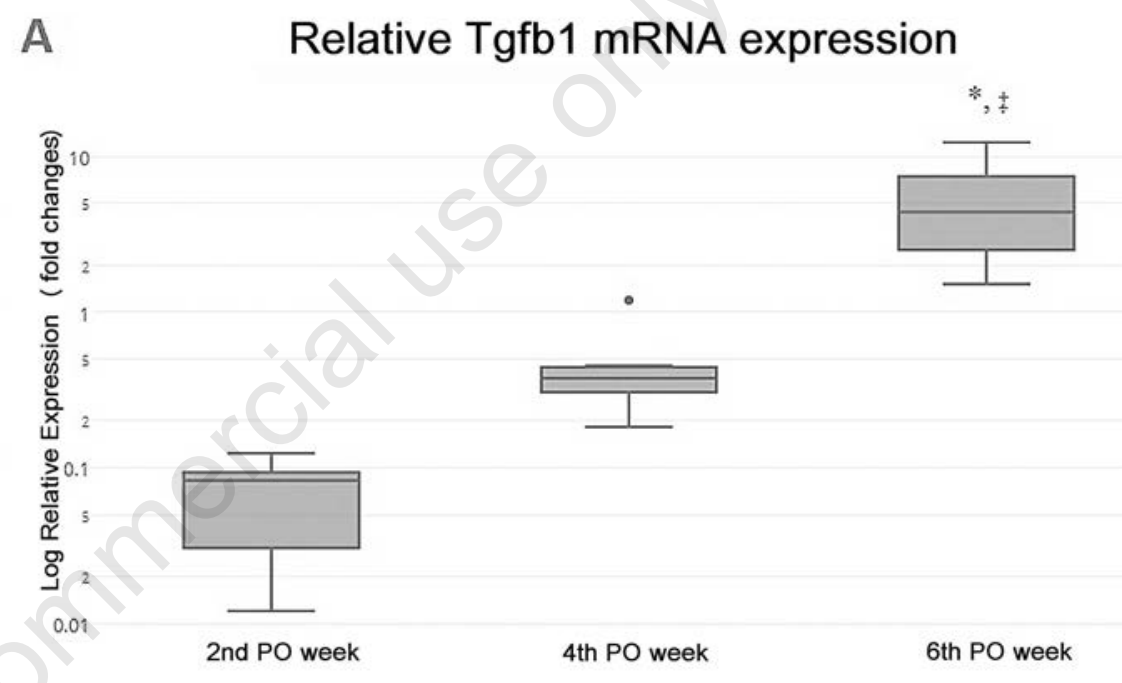

B

\section{Relative Apln mRNA expression}

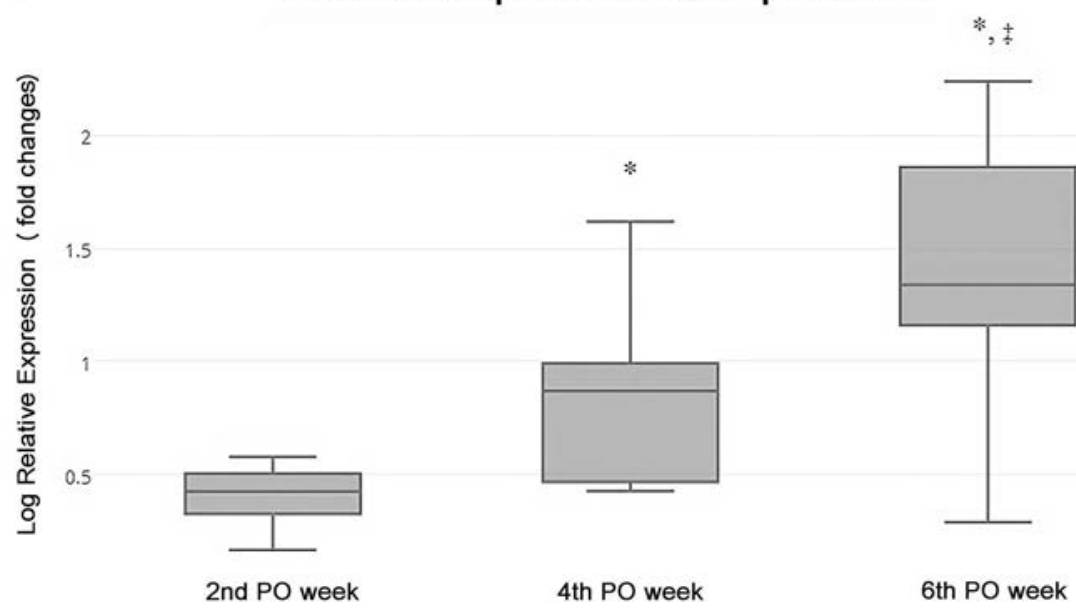

Figure 3. mRNA expression level of transforming growth factor- $\beta 1$ ( Tgfbl) (A) and apeline $(A p l n)(\mathrm{B})$ genes in the liver of bile duct ligature group compared to control group by real-time quantitative polymerase chain reaction. The differences are expressed as "fold change". Note massive overexpression of $T g f b 1$ on $6^{\text {th }}$ postoperative week (A) and progressive linear elevation of Apln (B). PO, postoperative; ${ }^{*} \mathrm{P}<0.001 \mathrm{BDL}$ versus control group on each week; ${ }^{\ddagger} \mathrm{P}<0.001 \mathrm{BDL} 6^{\text {th }} \mathrm{PO}$ week versus $\mathrm{BDL} 2^{\text {nd }} \mathrm{PO}$ week. 
including apoptosis of hepatocytes, enhances hepatocyte destruction, and mediate hepatic stellate cell and fibroblast activation resulting in a wound healing response with extracellular matrix deposition. TGF- $\beta 1$ also regulates activation and recruitment of inflammatory cells into injured liver, and transdifferentation of some liver-resident cells. ${ }^{22}$ In our study, $T g f b 1$ gene had an exponential overexpression on the $6^{\text {th }}$ postoperative week in accordance to what previous authors have reported. ${ }^{22}$ Apelin, the endogenous ligand of angiotensin-like-receptor 1 , is an emergent peptide involved in liver disease. Recent studies have demonstrated that apelin is overexpressed in livers from both cirrhotic human and rats. ${ }^{23}$ In addition, apelin modulates splanchnic angiogenesis and portosystemic collateral vessel formation in an experimental model of portal hypertension in rats. Apelin expression in rodents has been evaluated in other non-cholestatic adult animal models. ${ }^{24}$ Chen et al. demonstrated that apelin is overexpressed in livers of biliary atresia patients according to progression of disease, markedly activated in end-stage cirrhosis. Significant linear correlations were observed between apelin mRNA level and liver fibrosis, serum total bilirubin and the grade of esophageal varices. Since apelin expression level accurately reflects the severity of hepatic fibrosis, Chen et al. proposed that it could be used as a prognostic factor in biliary atresia patients, to estimate the timing of liver transplantation. ${ }^{25}$ Our current results confirm these findings on progressive apelin expression. Moreover, these findings support the use of apelin as a fibrosis and prognostic marker, because the rise in Apln gene expression levels is significantly elevated in BDL animals as early as at $4^{\text {th }}$ postoperative week, while the classic $T g f b 1$ gene expression levels are statistically different at $6^{\text {th }}$ postoperative week.

In conclusion, bile duct ligature in young rats is a simple surgical model that recreates clinical, laboratory, histological and molecular findings of human biliary atresia. Bile duct ligature in young rats produces a progressive cholestatic injury, leading to liver fibrosis and related complications. Bile duct ligature in young rats is a good animal model to investigate therapeutic approaches against liver damage and portal hypertension in biliary atresia.

\section{References}

1. Hartley JL, Davenport M, Kelly DA.
Biliary atresia. Lancet 2009;374:1704-13.

2. Petersen C, Davenport M. Aetiology of biliary atresia: what is actually known? Orphanet J Rare Dis 2013;8:128.

3. Jiménez-Rivera C, Jolin-Dahel KS, Fortinsky KJ, Gozdyra P, Benchimol EI. International incidence and outcomes of biliary atresia. J Pediatr Gastroenterol Nutr 2013;56:344-54.

4. Kasai M, Watanabe K, Yamagata A, Takamura U. Surgical treatment of biliary atresia. Nihon-iji-shinpo 1957;15: 1730-32.

5. Feldman AG, Mack CL. Biliary atresia: clinical lessons learned. J Pediatr Gastroenterol Nutr 2015;61:167-75.

6. Petersen C. Biliary atresia: the animal models. Semin Pediatr Surg 2012;21: 185-91.

7. Chung-Davidson Y-W, Yeh C-Y, Li W. The sea lamprey as an etiological model for biliary atresia. Biomed Res Int 2015;2015:832943.

8. Cameron GR, Oakley CL. Ligation of the common bile duct. J Pathol Bact 1932;35:769-98.

9. Aller MA, Durán M, Ortega L, Arias JL, Nava MP, Prieto I, et al. Comparative study of macro- and microsurgical extrahepatic cholestasis in the rat. Microsurgery 2004;24:442-7.

10. Yang Y, Chen B, Chen Y, Zu B, Yi B, Lu K. A comparison of two common bile duct ligation methods to establish hepatopulmonary syndrome animal models. Lab Anim 2015;49:71-9.

11. Gibelli NEM, Tannuri U, de Mello ES, Rodrigues CJ. Bile duct ligation in neonatal rats: Is it a valid experimental model for biliary atresia studies? Pediatr Transplant 2009;13:81-7.

12. National Research Council. Guide for the care and use of laboratory animals. 8th ed. Washington DC: National Academies Press; 2011.

13. Medeiros MVMJ, Freitas LAR, Andrade ZA. Differences in hepatic pathology resulting from bile duct obstruction in young and old rats. Braz J Med Biol Res 1988;21:75-83.

14. Omori M, Evarts RP, Omori N, Hu Z, Marsden ER, Thorgeirsson SS. Expression of $\alpha$-fetoprotein and stem cell factor/c-kit system in bile duct ligated young rats. Hepatology 1997;25:1115-22.

15. Wolfensohn S, Lloyd M. Anaesthesia of laboratory animals. In: Wolfensohn S, Lloyd M, editors. Handbook of laboratory animal management and welfare. 3rd ed. Oxford: Blackwell Publishing: 2003. p. 107-37.

16. Andrade Wde C, Tannuri U, da Silva
LF, Alves VA. Effects of the administration of pentoxifylline and prednisolone on the evolution of portal fibrogenesis secondary to biliary obstruction-an experimental study in growing animals. J Pediatr Surg 2009;44:2071-7.

17. Russo P, Magee JC, Boitnott J, Bove KE, Raghunathan T, Finegold M, et al. Design and validation of Biliary Atresia Research Consortium histological assessment system for cholestasis in infancy. Clin Gastroenterol Hepatol 2011;9:357-62.

18. Moreira RK, Cabral R, Cowles RA, Lobritto SJ. Biliary atresia: a multidisciplinary approach to diagnosis and management. Arch Pathol Lab Med 2012;136:746-60.

19. Novo E, Cannito S, Paternostro C, Bocca C, Miglietta A, Parola M. Cellular and molecular mechanism in liver fibrogenesis. Arch Biomed Biophys 2014;548:20-37.

20. Junqueira LC, Bignolas G, Brentani RR. Picrosirius staining plus polarization microscopy, a specific method for collagen detection in tissue section. Histochem J 1979;11:447-55.

21. Ramm GA, Hoskins CA, Greco SA, Pereira TN, Lewindon PJ. Signal for hepatic fibrogenesis in pediatric cholestatic liver disease: review and hypothesis. Comp Hepatol 2004; (3Suppl.1):S5.

22. Gonçalves JO, Tannuri ACA, Coelho MCM, Bendit I, Tannuri U. Dynamic expression of desmin, $\alpha$-SMA and TGF$\beta 1$ during hepatic fibrogenesis induced by selective bile duct ligation in young rats. Braz J Med Biol Res 2014;47:850-7.

23. Yokomori H, Oda M, Yoshimura K, Machida S, Kaneko F, Hibi T. Overexpression of apelin receptor (APJ/AGTRL1) on hepatic stellate cells and sinusoidal angiogenesis in human cirrhotic liver. J Gastreoenterol 2011; 46:222-31.

24. Yoshiya S, Shirabe K, Imai D, Toshima $\mathrm{T}$, Yamashita $\mathrm{Y}$, Ikegami $\mathrm{T}$, et al. Blockade of the apelin-APJ system promotes mouse liver regeneration by activating Kupffer cells after partial hepatectomy. J Gastroenterol 2015;50:573-82.

25. Chen W, Oue T, Ueno T, Uehara S, Usui N, Fukuzawa M. Apelin is a marker of the progression of the liver fibrosis and portal hypertension in patients with biliary atresia. Pediatr Surg Int 2013;29: 79-85. 